\title{
Razão da não utilização de incentivos fiscais à inovação tecnológica da Lei do Bem por empresas brasileiras
}

Reason of not using the tax incentives to technological innovation of the "Law of Good" by Brazilian enterprises

Razones de la no utilización de los incentivos fiscales a la innovación tecnológica de la Ley Buena por las empresas brasileñas

\section{Oderlene Vieira de Oliveira}

Doutora em Administração de Empresas pela Universidade de Fortaleza (UNIFOR)

Professora Adjunta do Programa de Pós-graduação em Administração da Universidade de Fortaleza (UNIFOR)

Endereço: Rua Bento Albuquerque, 2500, apto 1002, bloco 3, Bairro Cocó

CEP: 60192-050 - Fortaleza/CE - Brasil

E-mail: oderlene@unifor.br

Telefone: (85) 987069691

\section{Elisangela Freires Zaba}

Graduada em Administração de Empresas

Endereço: Rua Bento Albuquerque, 2500, apto 1002, bloco 3, Bairro Cocó

CEP: 60192-050 - Fortaleza/CE - Brasil

E-mail: elis.freires@hotmail.com

Telefone: (85) 98778-5589

\section{Sérgio Henrique Arruda Cavalcante Forte}

Doutor em Administração de Empresas pela Fundação Getúlio Vargas - EAESP

Professor Titular do Programa de Pós-graduação em Administração da Universidade de Fortaleza (UNIFOR)

Endereço: Av. Paisagística, 100, apto 804, bloco 3

CEP: 60812-535 - Fortaleza/CE - Brasil

E-mail: sergioforte@unifor.br

Telefone: (85) 986050078

Artigo recebido em 20/09/2013. Revisado por pares em 28/12/2016. Reformulado em 01/03/2017. Recomendado para publicação em 16/03/2017 por Carlos Eduardo Facin Lavarda (Editor-Chefe). Publicado em 30/04/2017. 


\section{Resumo}

Partindo da existência de incentivos fiscais para a atividade inovadora, a exemplo da Lei $\mathrm{n}^{\mathrm{o}}$ 11.196/2005 (chamada Lei do Bem) que ampliou os benefícios existentes e instituiu outros novos para estimular a inovação, definiu-se como problema de pesquisa a seguinte questão: quais as razões da não utilização de incentivos fiscais à inovação tecnológica da Lei do Bem pelas empresas brasileiras? Assim, o objetivo geral da presente pesquisa consistiu em identificar as razões da não utilização de incentivos fiscais à inovação tecnológica da Lei do Bem por empresas privadas de capital aberto, listadas no segmento novo mercado de governança corporativa da BM\&FBovespa. Para tanto, realizou-se pesquisa do tipo qualitativa, documental e descritiva, viabilizada por meio da análise dos relatórios contábeis, bem como dos relatórios que contêm informações sociais, e por meio de questionário respondido por 125 companhias. Os resultados possibilitaram concluir que as companhias que investiram em P\&D e não se utilizaram da Lei do Bem não se beneficiaram ou porque estavam com problemas fiscais, ou porque fecharam o ano de 2010 com prejuízo fiscal. A importância deste estudo decorre do fornecimento de informações atuais e significativas das razões para as empresas não estarem se beneficiando dos incentivos fiscais à inovação tecnológica, tema que até agora vinha sendo negligenciado pelos pesquisadores. Espera-se, assim, que os conhecimentos adquiridos a partir desta investigação possam contribuir para o futuro desenvolvimento desta linha de pesquisa, bem como promover nas entidades reflexão para a solução dos entraves apresentados.

Palavras-chave: Incentivos fiscais; Lei do Bem; Inovação tecnológica; Pesquisa \& Desenvolvimento

\section{Abstract}

Starting from the tax incentive existences for the innovative activity, exemplifying the Law No. 11.196/2005 (called Lei do Bem (Law of Good) that extended the existing benefits and instituted new ones to stimulate innovation, it was defined as research problem the following question: which are the reasons of not using the tax incentives for technological innovation from "Lei do Bem" (Law of Good) by Brazilian Enterprises? Thus, the current research overall objective is to identify the reasons of not using tax incentives for technological innovation from Lei do Bem (Law of Good) by private publicly traded enterprises, listed on the New Market segment of the $B M \&$ FBovespa. Therefore, it was held a qualitative, documental and descriptive research becoming viable through accounting report analysis, as well as reports that contain social information and through questionnaire answered by 125 companies. The results enabled to conclude that enterprises that invested in $R \& D$ and did not use the Law of Good (Lei do Bem) did not benefit either because they had tax problems or finished the year 2010 facing tax loss. The importance of this study is about current and significant information of the reasons for enterprises are not taking advantage of tax incentives to technological innovation, a subject that until now had been neglected by researchers. Therefore, it is expected, that the knowledge acquired from this research can contribute to the future development of this research line, as well as to stimulate insight entities to solve the obstacles presented.

Keywords: Tax incentives; Law of Good; Technological innovation; Research \& Development

\section{Resumen}

A partir de la existencia de incentivos fiscales a la actividad innovadora, como la Ley $N^{\circ}$ 11.196/2005 (llamada Ley Buena), que amplió los beneficios existentes e instituyó nuevas para estimular la innovación se definió como problema de investigación la siguiente pregunta: 
¿Cuales las razones de la no utilización de los incentivos fiscales a la innovación tecnológica de la Ley Buena por las empresas brasileñas? Por lo tanto, el objetivo general fue identificar las razones de la no utilización de los incentivos fiscales a la innovación tecnológica de la Ley Buena por las empresas privadas, que figuran enumeradas en el nuevo segmento de mercado de gobierno corporativo de la BM\&FBovespa. Por tanto, esta investigación cualitativa, documental y descriptivo fue posible a través del análisis de los informes financieros y los informes que contienen información social y por medio de un cuestionario con 125 empresas. Los resultados permitieron concluir que las empresas que han invertido en investigación y desarrollo y que no se utilizan la Ley Buena, no se beneficiaron o porque eran problemas de impuestos o porque cerraron el año 2010 con la pérdida de impuestos. La importancia de este estudio es a través de la provisión de información actualizada y significativa por las razones que las empresas no están aprovechando los incentivos fiscales a la innovación tecnológica, un tema que hasta ahora estaba siendo descuidada por los investigadores. Se espera, por tanto, que el conocimiento obtenido de esta investigación contribuirá al desarrollo futuro de esta línea de investigación, y promover las entidades una reflexión para la solución de sus obstáculos presentado.

Palabras clave: Incentivos fiscales; Ley Buena; Innovación tecnológica; Investigación y desarrollo

\section{Introdução}

Em face das novas características do mercado, o ambiente competitivo das empresas se tornou mais desafiante e exigente. E, consequentemente, as empresas tiveram que se preparar para a adoção de estratégias inovadoras. De acordo com Sennes (2011) o tema da inovação está ganhando um espaço importante tanto na agenda pública como na estratégia das empresas no Brasil, assim como em alguns outros países. O autor ressalta que existe uma significativa correlação entre o nível de investimento de um país no tema da inovação e o grau de exposição e de inserção de suas empresas no mercado internacional. A abertura de novos mercados e a capacidade de ampliar participação nos mercados existentes dá à inovação uma posição estratégica na concorrência entre as empresas.

Assim, a inovação tecnológica permite às empresas vantagem competitiva, quer agregando valores aos seus produtos, inovando-os ou obtendo redução de custos dos mesmos por meio de avanços técnicos produtivos, o que favorece diferenciar seus produtos dos da concorrência (CIPOLLA; CAVALCANTI; SOUZA, 2007).Do ponto de vista das firmas, a inovação pode ser responsável pela competitividade e pelo sucesso ou fracasso no ambiente competitivo do mercado. Do ponto de vista da sociedade, a inovação gerada pelas firmas é responsável por parte considerável do avanço tecnológico e do crescimento econômico (CORREIA; MOITA, 2011).

O Brasil adota várias medidas que procuram incentivar e subsidiar a atividade inovadora, a exemplo da Lei $\mathrm{n}^{0}$ 11.196/2005 (chamada "Lei do Bem"), que ampliou os benefícios existentes e instituiu outros novos para estimular a inovação. Estes benefícios vão desde os fiscais para a atividade inovadora, isenção tributária de insumos estratégicos, linhas de financiamento - Banco Nacional de Desenvolvimento Econômico e Social (BNDES) e da Financiadora de Estudos e Projetos (FINEP) -, formação de recursos humanos etc. Enfim, o Brasil gasta recursos e faz um grande esforço, comparado a países com renda per capita semelhante, para incentivar a inovação tecnológica (CGEE/ANPEI, 2008).

Jensen, Menezes Filho e Sbragia (2004) salientam que um dos principais fatores que influenciam ativamente o processo de inovação tecnológica são os gastos em Pesquisa e 
Desenvolvimento (P\&D). Crisótomo e Gonzáles (2006) ressaltam que apesar da dificuldade de obtenção de dados, até mesmo em países desenvolvidos pesquisas acadêmicas sobre as relações de gastos em intangíveis com o mercado e o desempenho da empresa têm evoluído, com destaque para os gastos, ou investimentos, em P\&D.

Nesse contexto, em que o Brasil está vivendo um cenário favorável aos investimentos em inovação por parte das empresas privadas, definiu-se como problema de pesquisa a seguinte questão: quais as razões da não utilização de incentivos fiscais à inovação tecnológica da Lei do Bem pelas empresas brasileiras? Para tanto, o objetivo geral consistiu em identificar as razões da não utilização de incentivos fiscais à inovação tecnológica da Lei do Bem por empresas privadas de capital aberto, listadas no segmento novo mercado de governança corporativa da BM\&FBovespa.

Especificamente, objetiva-se investigar o total de empresas listadas no segmento novo mercado de governança corporativa da BM\&FBovespa que se beneficiou dos incentivos fiscais da Lei do Bem em 2010, e o total de empresas que investiu em P\&D em 2010 e que não utilizou o incentivo da Lei do Bem.

Acerca da questão de pesquisa, foram adotados dois pressupostos, provenientes da própria condição das empresas investigadas - por serem empresas privadas de capital aberto -, listadas no segmento novo mercado da BM\&FBovespa, e que por esta condição são altamente profissionalizadas e condicionadas a se beneficiarem de incentivos governamentais.

O primeiro pressuposto é que o desconhecimento da Lei não é um motivo, e o segundo é que mesmo que as empresas tenham condições de se habilitar nos critérios impostos pela Lei, a não participação por não encaminhamento dos formulários exigidos não é realidade para o caso do tipo de empresa aqui estudado.

A escolha por se estudar a não utilização dos incentivos fiscais à inovação tecnológica da Lei do Bem se deve, conforme já destacado, à importância da inovação tecnológica para a competitividade das empresas e também à necessidade de elas melhorarem a gestão tecnológica e investirem cada vez mais em Pesquisa, Desenvolvimento e Inovação (PD\&I), com o intuito de aumentar a competitividade de seus produtos e serviços e, por consequência, competirem em bases mais sólidas e com produtos de maior valor agregado.

\section{Referencial Teórico}

\subsection{Inovação Tecnológica}

A inovação na teoria econômica vem sendo discutida há pelo menos um século. Como fruto dessa discussão houve a criação de um arcabouço teórico que se propõe a explicar a dinâmica da inovação (BARBOSA, 2011). Um dos autores mais relacionados com a inovação na teoria econômica é Schumpeter. Assim, de acordo com Schumpeter (1982), a evolução econômica é explicada por uma história de revoluções, que ilustra um processo de mutação contínua de dentro das próprias estruturas, incessantemente destruindo o antigo para dar espaço para o novo, ou seja, a inovação.

No Brasil, desde a década de 1990 a dimensão tecnológica vem assumindo um papel preponderante nos processos sociais, econômicos e ambientais. Trigueiro (2002) aponta alguns investimentos em políticas de inovação nessa década, como por exemplo, a criação de fundos setoriais para financiamento de pesquisas, a formulação da Lei da Inovação e o crescimento da importância das Incubadoras de Empresas. Nesse sentido, Barbosa (2011) destaca que a geração de inovações é um processo dinâmico e complexo, composto por uma variedade de agentes que 
influenciam a seleção das trajetórias e paradigmas tecnológicos.

Há uma tendência em associar a inovação só com a invenção ou a criação de novos produtos. Mas essa inovação do produto é apenas um dos vários tipos de inovação (HJALAGER, 1997). Hjalager (1997) e Perdomo-Ortiz, Gonzales-Benito e Galende (2006) mencionam outros tipos, tais como o clássico processo de inovações (onde o processo de produção é alterado), a manipulação de informações de inovações (onde novas formas de gestão do conhecimento são adotadas), as inovações de gestão (onde a maneira pela qual uma empresa é gerida é alterada) e as inovações institucionais (onde a estrutura da organização é alterada). Para Schumpeter (1988), a inovação não está associada somente à criatividade com a geração de novas ideias, mas também com a iniciativa e a tomada de riscos.

Inovação implica trazer novas ideias para fruição no mercado, satisfazendo as demandas ou criando novas necessidades, em um processo que melhora o bem-estar geral. A definição proposta pela Organisation for Economic Co-operation and Development (OECD) sublinha os novos modos de pensar inovação:

\begin{abstract}
Uma inovação tecnológica de produto é a implantação/comercialização de um produto com características de desempenho aprimoradas, de modo a fornecer objetivamente ao consumidor serviços novos ou aprimorados. Uma inovação de processo tecnológico é a implantação/adoção de métodos de produção ou comercialização novos ou significativamente aprimorados. Ela pode envolver mudanças de equipamento, recursos humanos, métodos de trabalho ou uma combinação destes. (OECD, 2004, p.21).
\end{abstract}

Schumpeter (1982) relata que as inovações são definidas como uma alteração relevante em uma das cinco esferas, sendo elas: a) introdução de um novo bem; b) introdução de um novo método de produção (baseado na descoberta de uma nova tecnologia ou nova maneira de manejar comercialmente uma mercadoria); c) abertura de um novo mercado; d) descoberta de uma nova fonte de matéria-prima; e d) reorganização de um processo produtivo, ou mudança significativa na posição de concorrência.

Ainda de acordo com aquele autor, as mudanças espontâneas que ocorrem na direção do desenvolvimento são movidas pela possibilidade de obtenção do lucro excepcional. O empresário inovador (o agente promotor da inovação por excelência - aquele quem faz a recombinação das forças produtivas e obtém os lucros resultantes da inovação) obteria lucros excepcionais advindos da exploração de sua inovação. No entanto, esse benefício extra só seria obtido até que outros empresários também incorporassem esta inovação em seus processos produtivos, reduzindo esta taxa a um patamar comum. Esses lucros podem ser obtidos devido a um posicionamento monopolista no provimento de um produto à sociedade ou, no caso de inovações de processo, pelo aumento da produtividade da firma, consequente redução de custos e aumento da margem de lucro. Não obstante, este não é o único motivo pelo qual as firmas geram e adotam inovações.

Kemp et al. (2000) afirmam que as inovações envolvem um complexo sistema de interações entre as firmas e o ambiente, sendo que este ambiente pode ser visto de duas maneiras distintas. Em um primeiro nível, existem interações entre firmas, seus consumidores e fornecedores, particularmente quando isso envolve estreita interação entre produtores e usuários de tecnologias. E o segundo nível envolve fatores mais amplos, como: o contexto sociocultural, o marco institucional e organizacional, a infraestrutura, o processo de criação e distribuição de conhecimento científico, dentre outros. 


\title{
2.2 Pesquisa \& Desenvolvimento (P\&D)
}

De acordo com Stickney e Weil (2010), a P\&D é uma forma de atividade econômica realizada com a expectativa de descobrir novos conhecimentos que permitam criar ou aperfeiçoar produtos, processos ou serviços. Já para Schmidt, Fernandes e Santos (2006) são investimentos realizados para gerar novos produtos, aperfeiçoar produtos antigos ou reduzir custos operacionais, com o objetivo de benefícios futuros.

Stickney e Weil (2010) ressaltam que as empresas bem sucedidas geralmente gastam com P\&D por várias razões, como por exemplo: a) procurar desenvolver competência tecnológica ou de marketing que lhes propicie vantagem competitiva sobre os concorrentes; $b$ ) explorar possíveis aplicações da tecnologia existente, visando ao desenvolvimento de novos produtos ou ao aperfeiçoamento de produtos antigos; c) participar de concorrências do governo; ou d) simplesmente realizar pesquisa básica, sem nenhum produto específico em mente.

\begin{abstract}
Em termos de estratégias competitivas, $P \& D$, se usada de forma adequada na indústria, provoca uma redução de custos, abre novos mercados e aumenta a produtividade em escala global. Sendo assim, pode-se afirmar que os investimentos em P\&D é condição necessária para melhorar a competitividade da empresa (MARTIN, 2001, p. 6).
\end{abstract}

Estudos anteriores indicam que o setor mais ativo no campo de P\&D é o de Softwares, assim como os demais setores de tecnologias da informação e comunicação (TICs). As ações de informática e atividades correlatas representam entre $2 \%$ a $16 \%$ do total do dispêndio em P\&D por empresas nos países da Organização de Cooperação e Desenvolvimento Econômicos (OCDE, 2003). Ainda de acordo com a $\operatorname{OCDE}(2003$, p. 165, 166):

\footnotetext{
é nos Estados Unidos que são efetuadas as despesas empresariais mais expressivas em P\&D no setor de informática e atividades correlatas, com quase USD 14 bilhões em paridade de poder de compra em 1997, ou seja, mais de dez vezes a importância despendida no mesmo período pelos países da OCDE classificados em segundo e terceiro lugares: Japão e Reino Unido. Canadá, Alemanha, França e Austrália situamse também entre os países membros cujas despesas com P\&D nesse setor são as mais elevadas.
}

A OCDE, em relatório publicado em 2008, compara dados de ciência e tecnologia de países membros e não membros (África do Sul, Brasil, Chile, China, Índia, Israel e Rússia) mostrando como está o cenário da inovação no mundo e quais são as tendências atuais. As principais tendências identificadas pelo estudo em relação à pesquisa, tecnologia e inovação foram: i) inovações crescentemente dirigidas pelo conhecimento; ii) rápida modificação na organização da pesquisa, que, viabilizada pelos avanços na informática, se apoia em colaboração e em conhecimento compartilhado; iii) com a aceleração da globalização tem havido uma rápida melhoria na conectividade e no desenvolvimento de plataformas e padrões tecnológicos; e iv) mudanças nos mercados, na tecnologia e no ambiente concorrencial (IEDI, 2008).

Com base naquele mesmo relatório, Sennes (2011) relata que, se comparando os dados brasileiros com outros países dos BRICS (Brasil, Rússia, Índia, China e África do Sul) e dos países membros da OCDE, pode-se chegar a algumas constatações. A primeira constatação é a baixa intensidade de investimentos em P\&D no Brasil - 1,02\% em 2006 - enquanto a média da OCDE ficou em torno de 2,26\%. A China, país que disputa com o Brasil a atração de investimento direto estrangeiro (IDE), ampliou sua intensidade de P\&D de 0,95\% em 2001 para 
1,42\% em 2006 e tem como meta alcançar o patamar de 2\% do PIB em 2010. A meta do Brasil estabelecida no Plano de Aceleração do Crescimento (PAC) de Ciência, Tecnologia \& Inovação (C,T\&I) é de 1,5\%. O relatório cita alguns dos obstáculos encontrados pelas empresas para a geração de inovação, identificados na Pesquisa de Inovação (Pintec) (o custo, o risco econômico e a escassez de pessoal qualificado) e ressalta que a promulgação da Lei de Inovação deverá ajudar na dissolução destes problemas e consequentemente na ampliação dos investimentos em atividades inovadoras.

No Brasil, a importância do desenvolvimento da infraestrutura tecnológica como suporte à atividade produtiva tornou-se mais visível a partir da década de $1990 \mathrm{com}$ a abertura comercial, momento em que o País optou pelo modelo de inserção competitiva no comércio mundial. Se comparadas com as empresas estrangeiras, as brasileiras investem pouco em P\&D (JENSEN; MENEZES FILHO; SBRAGIA, 2004).

Jensen, Menezes Filho e Sbragia (2004) ressaltam que isso se deve, em parte, à falta de estabilidade econômica que reinou por muito tempo no Brasil, dificultando o planejamento de longo prazo, como é o caso do investimento em P\&D. O pequeno grau de abertura da economia, que no passado protegia as indústrias brasileiras da competição externa, também influenciou negativamente o processo de geração de inovações tecnológicas. Esta situação, vivida em um passado recente, vem se modificando gradativamente com a abertura comercial da década de 1990 e com a estabilização macroeconômica a partir de 1994.

Em pesquisa realizada pela Associação Nacional de Pesquisa, Desenvolvimento e Engenharia das Empresas Inovadoras (ANPEI, 2007), detectou-se que a tendência em P\&D se concentra em grandes empresas, está mais voltada ao desenvolvimento experimental do que à pesquisa básica ou aplicada, possui baixíssimo número de mestres e doutores alocados, aplica majoritariamente capital próprio da empresa e possui um resultado fraco em termos de registros de patentes. A seguir, apresenta-se o tema "incentivos fiscais à inovação".

\subsection{Incentivos Fiscais à Inovação}

Incentivo fiscal é um conceito da ciência das finanças. Situa-se no campo da extrafiscalidade e implica redução da receita pública de natureza compulsória ou a supressão de sua exigibilidade. É um instrumento do dirigismo econômico e visa desenvolver economicamente determinada região ou certo setor de atividade (HARADA, 2011).

Os incentivos fiscais à inovação tecnológica são mecanismos de renúncia fiscal por meio dos quais o governo vem a apoiar indiretamente os investimentos nas atividades de PD\&I pelas empresas (ROCHA; SOARES; CASSONI, 2011).

Incentivos fiscais à inovação (IFI) são instrumentos utilizados pelos governos para interferir na quantidade e qualidade das atividades de inovação. Geralmente, algum benefício fiscal, como deduções ou redução de tributos, é concedido com vistas a ampliar as atividades de inovação. (CALZOLAIO; DATHEIN, 2012, p. 2).

Segundo Lhuillery (2005, apud CALZOLAIO; DATHEIN, 2012, p. 3), o incentivo fiscal para P\&D é uma das ferramentas dentre as políticas de Ciência e Tecnologia que foi intensificado recentemente. Especificamente no Brasil o incentivo fiscal à inovação tecnológica foi implantado no exercício de 1993, através da Lei $\mathrm{n}^{\circ} 8.661$ que regulava o Programa de Desenvolvimento Tecnológico Industrial (PDTI), exceção do Canadá (desde 1944) e do Japão (desde1967). 
Os incentivos fiscais à P\&D são uma tendência internacional apresentando algumas vantagens que os tornam atraentes para os formadores de políticas: (1) são baseados em alocações de mercado; (2) não discriminam setores; e (3) estão prontamente disponíveis às empresas, com baixo custo administrativo para o governo. (ARAÚJO, 2010, apud COELHO, 2011, p. 60).

Calzolaio e Dathein (2012) afirmam que "a Política Industrial, Tecnológica e de Comércio Exterior (PITCE) implementada em 2004, no início do primeiro governo Lula, foi base para a formulação de uma nova matriz jurídica voltada à promoção da produção residente". Nesse âmbito surgiu um novo modelo de IFI no Brasil, compreendido na Lei $n^{\circ}$ 11.196/05, intitulado como Lei do Bem.

Atualmente os incentivos fiscais à inovação tecnológica fazem parte da Estratégia Nacional de Ciência, Tecnologia e Inovação (ENCTI) para o período de 2011 a 2014. Além de constituir num dos elos com as demais políticas do Governo Federal, tais como PAC, Política de Desenvolvimento Produtivo (PDE) e, mais recentemente, com o Plano Brasil Maior que estabelece uma política industrial, tecnológica, de serviços e de comércio exterior embasada no estímulo à inovação e à produção nacional para alavancar a competitividade da indústria nos mercados interno e externo (MCTI, 2011).

\begin{abstract}
A perfeita sintonia da Lei do Bem com todas essas diretrizes do Governo Federal tem dado o devido suporte para sedimentar as bases para promover a inovação tecnológica no País. Inclusive, com o reforço do modelo de mecanismo de cooperação com empresas de pesquisa (universidades, institutos de pesquisa e redes de pesquisas setoriais), tem facilitado bastante para um melhor aproveitamento do capital intelectual disponível no nosso País. Tudo isto representa uma forte sinalização da determinação do Governo Federal para que, no período de 2011 a 2014, possa dar sua contribuição para transformar o Brasil numa potência científica e tecnológica. (MCTI, 2011, p. 4).
\end{abstract}

Ainda de acordo com o MCTI (2011, p. 22), os dados registrados no Relatório Anual de Utilização dos Incentivos Fiscais - ano base 2010 - apontam que em relação ao exercício de 2009, 635 empresas optaram por se beneficiar dos incentivos da Lei do Bem; já no exercício de 2010 foram 875 empresas, ou seja, houve um aumento de $38 \%$ em relação ao ano anterior. "Porém, percebe-se grandes obstáculos para implementação da Lei do Bem, como estratégia eficaz de estimulo à inovação" (BASTOS, 2003, p. 253).

Inquestionavelmente, os incentivos fiscais às empresas que investem em PD\&I representam um marco estratégico importante para o país, sendo que tais benefícios têm contribuído com o despertar de várias organizações para melhorar a gestão tecnológica e investir cada vez mais em PD\&I, aumentando, assim, a competitividade dos seus produtos e serviços.

\title{
2.3.1 Lei do Bem
}

De acordo com Guimarães (2006, apud ZUCOLOTO, 2010, p. 14),

até a introdução da Lei do Bem, a política de incentivos fiscais à inovação seguia as determinações da Lei $n^{\circ} 8.661 / 93$ (incentivos fiscais e competitividade), que representou a retomada do mecanismo como instrumento da política tecnológica no Brasil.

Já Moreira et al. (2007, p. 36) comenta sobre a Lei $n^{\circ} 11.196$ ressaltando os artigos que 
consolidam os incentivos fiscais.

A Lei $\mathrm{n}^{\circ} 11.196$, de 21 de novembro de 2005, que até sua conversão em lei tramitou como "MP do Bem" (Medida Provisória 252/2005 e, posteriormente, Medida Provisória 255/2005), foi regulamentada pelo decreto $\mathrm{n}^{\mathrm{0}} 5.798$, de 7 de junho de 2006. Os artigos 17 a 26 de seu Capítulo III consolidam os incentivos fiscais que as pessoas jurídicas podem usufruir de forma automática, desde que realizem pesquisa tecnológica e desenvolvimento de inovação tecnológica. Esse capítulo foi editado por determinação da Lei da Inovação.

A Lei no 11.196/2005 compila a legislação existente de incentivos fiscais do setor, revogando toda a bateria existente. São mantidos os incentivos em vigor, tal como modificados pela legislação superveniente a sua promulgação. Assim, em sua maior parte, o projeto em nada inova, e nada modifica. No entanto, generaliza todos os incentivos, sem condicioná-los, em lei, a qualquer aprovação prévia. Tal possibilidade se abre, porém, na regulamentação, que é condição indispensável de eficácia da lei proposta (BARBOSA, 2006).

Ainda segundo Barbosa (2006), três pontos inovam o sistema existente:

- Prevê-se, como sugerido pela Lei 10.637/02, dedução múltipla de despesas em P\&D, em $160 \%$ do despendido. Tal múltiplo pode chegar a $180 \%$, em função dos pesquisadores empregados, ou até a $200 \%$, em função das patentes e cultivares concedidos.

- Declara-se que as importâncias repassadas a micro e pequenas empresas para efetuar, em nome e por conta da comitente, P\&D são dedutíveis (como sempre foram), mas não têm a natureza de receita da beneficiária. Isso, teoricamente, isentaria tais importâncias de incidência de tributos e contribuições federais.

- A dedução múltipla limita-se ao imposto devido no exercício, sem carry over. No entanto, as empresas dedicadas exclusivamente a $\mathrm{P} \& \mathrm{D}$ podem carregar o valor dos dispêndios para os exercícios seguintes; tais empresas podem também computar os pagamentos feitos aos sócios pesquisadores na base do benefício.

Conforme o decreto $\mathrm{n}^{\mathrm{o}} 5.798$, de 7 de junho de 2006, que regulamenta os incentivos fiscais às atividades de pesquisa tecnológica e desenvolvimento de inovação tecnológica:

Art. $1^{\circ}$ Sem prejuízo das demais em vigor aplicáveis à matéria, a pessoa jurídica, relativamente às atividades de pesquisa tecnológica, poderá utilizar de incentivos fiscais, conforme disciplinado neste decreto.

Art. $2^{\circ}$ Para efeitos desse Decreto, considera-se:

I - inovação tecnológica: a concepção de novo produto ou processo de fabricação, bem como a agregação de novas funcionalidades ou características ao produto ou produto que implique melhorias incrementais e efetivo ganho de qualidade ou produtividade, resultando maior competitividade no mercado;

II - pesquisa tecnológica e desenvolvimento de inovação tecnológica, as atividades de:

a) pesquisa básica dirigida: os trabalhos executados com o objetivo de adquirir conhecimentos quanto à compreensão de novos fenômenos, com vistas ao desenvolvimento de produtos, processos ou sistemas inovadores;

b) pesquisa aplicada: os trabalhos executados com o objetivo de adquirir novos conhecimentos, com vistas ao desenvolvimento ou aprimoramento de produtos, processos e sistemas;

c) desenvolvimento experimental: os trabalhos sistemáticos delineados a partir de conhecimentos pré-existentes, visando a comprovação ou demonstração da viabilidade técnica ou funcional de novos produtos, processos, sistemas e serviços ou, ainda, um evidente aperfeiçoamento dos já produzidos ou estabelecidos; 
d) tecnologia industrial básica: aquelas tais como aferição e calibração de máquinas e equipamentos, o projeto e a confecção de instrumentos de medida específicos, a certificação de conformidade, inclusive os ensaios correspondentes, a normalização ou a documentação técnica gerada e o patenteamento do produto ou processo devolvido; e

e) serviços de apoio técnico: aqueles que sejam indispensáveis à implantação e à manutenção das instalações ou dos equipamentos destinados, exclusivamente, à execução de projetos de pesquisa, desenvolvimento ou inovação tecnológica, bem como à capacitação dos recursos humanos a eles dedicados.

Buscando facilitar o entendimento de quais segmentos da cadeia produtiva incidem os incentivos fiscais da Lei do Bem, o MTCI esclarece que"incidem somente no segmento onde ocorrem a pesquisa básica dirigida, a pesquisa aplicada e o desenvolvimento experimental (até a fase de desenvolvimento de protótipo), além da Tecnologia Industrial Básica (TIB) e os serviços de apoio técnico", conforme definidos no decreto $\mathrm{n}^{\circ}$ 5.798, de 07.06.2006 (decreto que regulamenta a Lei do Bem). (MCTI, 2011, p. 11).

É importante destacar que o capítulo III dos incentivos à inovação tecnológica, artigos17 a 26, só foi aplicável após a regulamentação do decreto $n^{\circ} 5.798$, de 07 de junho de 2006 . Ainda segundo o decreto 5.798/2006, é necessário que a pessoa jurídica preste anualmente informações eletrônicas através do preenchimento do formulário para informações sobre as atividades de pesquisa tecnológica e desenvolvimento de inovação tecnológica, ou FORMP\&D, nos quais as atividades anuais dos programas PD\&I das empresas são registrados tendo como prazo limite a data de 31 de julho do ano subsequente de cada exercício fiscal.

\subsubsection{Estudos relacionados}

Dentre os estudos acadêmicos nacionais relacionados ao tema foco da presente investigação, cabe destacar o de Formigoni (2008), de Bergamaschi (2009) e de Kuroki (2010). Formigoni (2008) avaliou os efeitos dos incentivos fiscais sobre a estrutura de capital e a rentabilidade de 590 companhias abertas brasileiras não financeiras. Os resultados do estudo sugeriram não haver correlação estatisticamente significativa entre incentivo fiscal e indicadores de estrutura de capital. Por outro lado, foi identificada correlação estatisticamente significativa entre incentivo fiscal e rentabilidade das empresas. Foram ressaltados ainda os seguintes achados: a) cerca de 1/3 de companhias são incentivadas; b) uma tendência de companhias comerciais, eletroeletrônicas, energia, máquinas industriais e papel/celulose não obterem incentivos fiscais; c) tendência de empresas do setor das telecomunicações obterem incentivos fiscais; d) as empresas incentivadas possuem maior tempo de operação no mercado; e) as empresas incentivadas também apresentaram maior nível de tributação; f) ausência de correlação entre crescimento de vendas e incentivos fiscais; g) tendência de queda no número de empresas incentivadas; e h) ausência de correlação estatisticamente significativa entre incentivo fiscal e os indicadores de endividamento das empresas.

Já Bergamaschi (2009) analisou a utilização dos incentivos fiscais para inovação tecnológica, previstos na Lei $11.196 / 05$ e no Decreto 5.798/06, no setor de serviços de telecomunicações. Os resultados possibilitaram identificar que: a) poucas empresas do setor estão se utilizando de incentivos fiscais para inovação tecnológica; b) as empresas que fizeram uso de incentivos fiscais apresentaram alterações significativas no que tange a centro tecnológico próprio e outros itens de infraestrutura voltados para PD\&I, bem como uma integração maior entre todas as áreas envolvidas com a inovação tecnológica; c) as empresas que não se beneficiaram dos incentivos fiscais previstos na Lei 11.196/05 e no Decreto 5.798/06 
apontaram como principal razão para a não utilização a falta de conhecimento, o que indica a necessidade de ações efetivas entre o setor público e privado para superar essa barreira.

Koruki (2010) também estudou o incentivo fiscal da inovação tecnológica, mas buscou identificar os fatores mais relevantes que motivam e dificultam as empresas a utilizarem o incentivo fiscal da inovação tecnológica. Para tanto, aplicou entrevistas com gestores de 11 empresas que atuavam em diversos segmentos. Os principais resultados possibilitaram verificar que as empresas brasileiras investem em inovação tecnológica para: a) obter vantagens competitivas em relação a seus concorrentes; b) manter os produtos atualizados e competitivos no mercado nacional e internacional; c) reduzir o número de reclamações de seus clientes; d) manter sua posição no mercado; e e) reduzir custos e sobreviver no mercado competitivo. Por outro lado, as empresas deixam de investir em inovação tecnológica devido: a) às incertezas quanto ao cenário econômico e às crises mundiais; b) ao orçamento disponível para investir em inovação tecnológica; c) à falta de uma legislação para proteção das empresas que investem em inovação tecnológica; d) à ausência de mão-de-obra especializada; e) à rigidez da estrutura organizacional das empresas; f) à redução da lucratividade em virtude dos investimentos em inovação; e g) aburocracias e restrições de sua matriz. Já os principais fatores que impedem as empresas de utilizar o Incentivo Fiscal da Inovação Tecnológica são: a) a exigência de regularidade fiscal; b) a obrigatoriedade de apurar o Imposto de Renda e a Contribuição Social sobre o Lucro Líquido com base no Lucro Real; c) a necessidade da implementação de controles para contenção dos gastos com inovação tecnológica; d) o desconhecimento dos benefícios da Lei do Bem; e) a falta de clareza na definição dos projetos que podem ser incluídos no incentivo; e f) a exigência de que os investimentos em inovação sejam realizados no país.

Vale também destacar o estudo técnico realizado por Araújo (2012, p. 6), cujo objetivo foi "analisar a evolução das políticas de apoio à inovação no Brasil, bem como suas medidas de apoio direto e indireto e seu arcabouço institucional de formulação e implementação de incentivos à inovação". Os resultados apontaram que o Brasil tem feito um esforço no sentido de alinhar suas políticas e estrutura de fomento à inovação ao que há de mais avançado no mundo. No entanto, é consenso entre especialistas de que o Brasil não tem conseguido transformar seu boom científico em inovação, já que os indicadores de inovação e participação mundial nas patentes não se alteraram significativamente na última década $(2000-2010)$. O aumento consistente tem sido em indicadores científicos, como formação de pós-graduados e participação em publicações indexadas. Já em relação à escala dos incentivos à inovação, estes têm sido acessados por poucas empresas, mesmo considerando o reduzido grupo de empresas inovadoras no Brasil. Araújo (2012, p.39) ressalta que "é preciso estudar as causas para esta baixa demanda".

No contexto internacional, vale destacar o trabalho de Atkinson (2007), que relatou que o crescimento no século XXI seria impulsionado em grande parte pela inovação. Muitas nações, incluindo a maior parte do Sudeste Asiático e da Europa, fizeram do desenvolvimento econômico liderado pela inovação um ponto central de suas estratégias econômicas nacionais. Seu uso agressivo de incentivos fiscais de P\&D é apenas um indicador desse compromisso. Infelizmente, os Estados Unidos não acompanharam o ritmo. Embora tenham fornecido o tratamento tributário mais generoso de $\mathrm{P} \& \mathrm{D}$ no final da década de 1980 entre os países da OCDE, em 2004 caíram para a $17^{\mathrm{a}}$ posição no ranking. Atkinson (2007) ressalta que enfrentar este novo desafio de competitividade exigirá que os decisores políticos tomem uma série de medidas, incluindo a melhoria da educação e o aumento significativo do financiamento para a investigação. No entanto, embora essas medidas sejam necessárias, elas não são suficientes para vencer o desafio da competitividade. A política precisa fazer mais do que aumentar a oferta de recursos de inovação (por exemplo, uma força de trabalho mais bem treinada e descobertas de 
pesquisas básicas mais elevadas); ela também deve estimular a demanda por parte das empresas para localizar mais da sua produção baseada na inovação nos Estados Unidos. Se os Estados Unidos continuarem a ser o local preeminente do mundo para a inovação tecnológica (e os altos empregos pagáveis que dela resultam), o Congresso precisará expandir significativamente o Crédito Fiscal de Pesquisa e Experimentação. Para isso, o Congresso deveria: a) tornar o crédito fiscal de I \& D permanente; b) dobrar a taxa do crédito regular de 20 por cento para 40 por cento; c) expandir o Crédito Simplificado Alternativo; d) criar um crédito plano para a I \& D colaborativa; e) permitir que as empresas paguem as despesas do primeiro ano com equipamentos de pesquisa; e f) isentar o crédito do Imposto Mínimo Alternativo corporativo.

\section{Metodologia}

Como é a questão da pesquisa que sugere a metodologia a ser utilizada (BECKER, 1997; GODIN; LIMA, 2002; QUIVY; COMPENHOUDT, 2008; STRAUSS; CORBIN, 2008; SILVERMAN, 2009) esta seção é iniciada expondo-se novamente o problema de pesquisa: quais as razões da não utilização de incentivos fiscais à inovação tecnológica da Lei do Bem por empresas brasileiras?

Existem algumas alternativas de indicadores de intensidade de inovações. Cabral (1998) salienta que estes indicadores se dividem basicamente em dois grupos: aqueles que incluem a medição de insumos inovadores, e aqueles que incluem saídas inovadoras. Hall, Mairesse e Mohnen (2010) citam a Pesquisa \& Desenvolvimento (Capital) como uma proxy para a entrada de inovação. A escolha de $\mathrm{P} \& \mathrm{D}$ como indicador na presente pesquisa se justifica pela adequação ao objetivo da pesquisa.

A elaboração da pesquisa se deu em quatro fases e em todas elas se adotou o método qualitativo (SILVERMAN, 2009), do tipo descritivo (COLLIS; HUSSEY, 2005). Utilizou-se também de pesquisa documental (CERVO; BERVIAN; DA SILVA, 2007).

$\mathrm{Na}$ primeira fase teve-se como objetivo identificar as empresas a serem investigadas, ou seja, as empresas brasileiras que investem em pesquisa e desenvolvimento. Para tanto, a base de dados consistiu em todas as empresas de capital aberto listadas no novo mercado, perfazendo um total de 125 empresas (data base 2011).

A segunda fase teve o objetivo de identificar, no Relatório Anual da Utilização dos Incentivos Fiscais, as empresas brasileiras listadas no segmento novo mercado da BM\&FBovespa que não estavam se beneficiando dos incentivos fiscais da Lei do Bem. Nesta fase foi utilizado um formulário. A pesquisa foi iniciada no segundo semestre de 2012, por meio do Relatório Anual da Utilização de Incentivos Fiscais ano base 2010, posto que o relatório com a posição de ano base de 2011 somente seria publicado em dezembro de 2012 ou em janeiro de 2013.

Já a terceira fase consistiu em identificar se essas empresas que não estão se beneficiando dos incentivos fiscais estão investindo em inovação, mais especificamente em P\&D. Averiguou-se nos relatórios contábeis das companhias investigadas (um total de 106), bem como nos relatórios que contêm informações sociais - mas que também apresentam informações financeiras, como é o caso do Relatório de Sustentabilidade do GRI -, se essas empresas fizeram algum investimento em P\&D no exercício de 2010. Todos esses relatórios foram colhidos a partir da Internet, nos sítios virtuais das empresas, no sítio da Comissão de Valores Mobiliários (CVM) e no sítio da BM\&FBovespa. Nesta etapa também foi utilizado um formulário de pesquisa.

A quarta fase consistiu no envio de um questionário para as 20 empresas identificadas

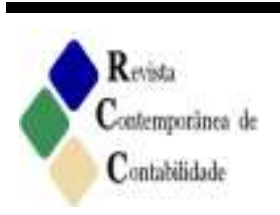


na terceira fase que estão investindo em $P \& D$ e não estão se beneficiando dos incentivos fiscais para identificar as razões da não utilização desses benefícios. O envio foi feito por meio de $e$ mail, que continha uma carta convite e o questionário (ver Apêndice A). Dos 20 e-mails enviados, oito (40\%) responderam. Crisótomo e Gonzáles (2006) ressaltam a dificuldade de obtenção de dados, até mesmo em países desenvolvidos, sobre gastos ou investimentos em pesquisa e desenvolvimento.

Para melhor visualização dos dados utilizou-se um gráfico, uma tabela e quadros (STEVENSON, 2001). Para analisar os dados foi adotada a técnica de Análise de Conteúdo, proposta por Bardin (2002). Na seleção da categoria optou-se pela grade de análise fechada,qual seja, motivo da não utilização do incentivo fiscal da Lei do Bem $n^{0}$ 11.196/2005, cujas subcategorias eram: a) desconhece a lei; b) está com problemas fiscais; c) não enviou o Formulário para Informações sobre as Atividades de Pesquisa Tecnológica e Desenvolvimento de Inovação Tecnológica (FORMP\&D) em tempo hábil; d) é uma empresa do setor de informática; e e) outros.

\section{Resultados e Análises}

\subsection{Empresas que se beneficiaram dos incentivos fiscais da Lei do Bem em 2010}

Foram identificadas inicialmente 125 empresas brasileiras listadas no segmento novo mercado de governança corporativa da BM\&FBovespa. Dessas, 19 estão se beneficiando dos incentivos fiscais da Lei do Bem (Tabela 1), de acordo com a relação constante no Relatório Anual da Utilização de Incentivos Fiscais, ano base 2010. Essa evidenciação permitiu que se concluísse que apenas $15 \%$ das empresas brasileiras listadas no segmento novo mercado da BM\&FBovespa investem em Pesquisa \& Desenvolvimento e estão se beneficiando dos incentivos fiscais da Lei do Bem. Tal resultado vai ao encontro dos achados de Bergamaschi (2009), que após analisar dados de 40 empresas do setor de serviços de telecomunicações sinalizou que poucas empresas do setor utilizavam os incentivos fiscais para inovação tecnológica. De acordo com Kuroki (2010), estima-se que apenas 14,5\% do total das empresas que realizam atividades de Pesquisa e Desenvolvimento (P\&D) no Brasil estejam usufruindo dos benefícios da Lei do Bem.

Tabela 1 - Empresas que se beneficiaram dos incentivos
fiscais da Lei do Bem em 2010
\begin{tabular}{c|r|r}
\hline \multirow{2}{*}{ Status } & \multicolumn{2}{|c}{ Frequência } \\
\cline { 2 - 3 } & Unid. & \multicolumn{1}{c}{$\%$} \\
\hline - Beneficiadas & 19 & 15 \\
- Não beneficiadas & 106 & 85 \\
\hline TOTAL & 125 & 100 \\
\hline Fonte: elaborado pelos autores (2012).
\end{tabular}

Uma segunda observação é que, das 19 empresas beneficiadas, 18 pertencem às regiões sudeste e sul do país, com predominância da região sudeste (14 das 19 empresas), sendo 13 do estado de São Paulo e apenas uma instalada na região nordeste (Quadro 1).

Apesar de estar crescendo o número de empresas que optam por se beneficiar dos incentivos fiscais da Lei do Bem (MCTI, 2011), percebem-se grandes obstáculos para sua implementação como estratégia eficaz de estímulo à inovação (BASTOS, 2003). De acordo com Araújo (2012), estes instrumentos atingem um número reduzido de empresas se considerarmos o total de firmas que têm atividades de P\&D no Brasil. 
Quadro 1 - Empresas beneficiadas por meio dos incentivos fiscais da Lei do Bem por Estado

\begin{tabular}{|l|cll|}
\hline \multicolumn{1}{|c|}{ Empresa } & Estado & \multicolumn{1}{c|}{ Empresa } & Estado \\
\hline AREZZO CO & MG & INDS ROMI & SP \\
AUTOMETAL & SP & IOCHP - MAXION & SP \\
CIA HERING & SC & LE LIS BLANC & SP \\
CREMER & SC & METAL LEVE & SP \\
EMBRAER & SP & NATURA & SP \\
ETERNIT & SP & PORTOBELLO & SC \\
FER HERINGER & SP & REDECARD & SP \\
FIBRIA & SP & TOTVS & SP \\
FLEURY & SP & WEG & SC \\
GRENDENE & CE & & \\
\hline
\end{tabular}

Fonte: elaborado pelos autores (2012).

\subsection{Companhias que investiram em P\&D em 2010 e não se beneficiaram da Lei do Bem em 2010}

Nas 106 empresas listadas na BM\&FBovespa/Novo Mercado que não constavam na lista do Relatório Anual da Utilização dos Incentivos Fiscais foi realizado um levantamento das demonstrações contábeis para averiguar se elas investiram em P\&D; constatou-se que apenas 24 empresas informaram, nos relatórios, investimentos em P\&D no exercício de 2010 (Quadro 2).

Quadro 2 - Empresas que investiram em P\&D por atividade principal

\begin{tabular}{|ll|}
\hline \multicolumn{1}{|c|}{ Nome na bolsa } & \multicolumn{1}{c|}{ Atividade principal } \\
\hline BEMATECH & Industrialização e comercialização de hardware \\
BRF FOODS & Holding operacional \\
CC DES IMOB & Setor de construção e infraestrutura \\
COPASA & Serviços de saneamento \\
COSAN & Produção de açúcar, etanol e cogeração de energia \\
CPFL ENERGIA & Gestão de participações societárias (holdings) \\
CYRELA REALT & Incorporação imobiliária \\
GAFISA & Incorporação imobiliária de edifícios escritórios e shopping centers. \\
LIGHT S.A & Participação em sociedades e exploração de serviços de energia elétrica \\
LLX LOG & Setor de logística portuária \\
LUPATECH & Fabricante de equipamentos e provedor de serviços para o setor de petróleo e gás \\
M. DIASBRANCO & Produção e comercialização de biscoitos, massas e farinhas \\
MAGNESITA S.A & Mineração, produção e comercialização de materiais refratários \\
MARFRIG & Produção e distribuição de alimentos processados, carnes e derivados. \\
MPX ENERGIA & Empresa de recursos naturais e de geração de energia elétrica \\
OHL BRASIL & Gerenciamento de concessão pública \\
POSITIVO INF & Fabricação de computadores \\
SABESP & Abastecimento de água, esgotamento sanitário, drenagem e manejo de águas pluviais \\
& urbanas \\
TECNISA & Incorporação \\
TRACTEBEL & Geração e comercialização de energia elétrica \\
TRIUNFO PART & Participação em empresas de concessões de rodovias, geração de energia e logística \\
ULTRAPAR & Distribuição de combustíveis, químicos e armazenagem para granéis líquidos \\
V- AGRO & Produção e comércio de produtos vegetais, industrialização e comercialização de \\
VIVER & biocombustíveis \\
\hline
\end{tabular}

Fonte: elaborado pelos autores (2012).

De acordo com a revista Época Negócios (2011), no âmbito global as mil empresas de capital aberto que mais investiram em pesquisa e desenvolvimento em 2010 elevaram os 
investimentos em 9,3\%, totalizando uma cifra de US\$550 bilhões. Trata-se de "uma forte recuperação com relação ao declínio de 3,5\% em 2009 - o que marca um retorno à trajetória de crescimento no longo prazo dos gastos com inovação", destaca a pesquisa da Booz \& Company (2011, apud ÉPOCA NEGÓCIOS, 2011, sem paginação).

Apesar da elevação constatada em 2010, no âmbito global ainda é baixo, no Brasil, o número de empresas listadas no segmento novo mercado que investem em $\mathrm{P} \& \mathrm{D}$, o que denota que esse aumento vem sendo no volume de investimentos das mesmas empresas.

\begin{abstract}
No Brasil, o investimento em inovação cresceu de R \$4 bilhões (US\$2,4 bilhões), em 2010, para R\$6,2 bilhões (US\$3,7 bilhões), em 2011. O investimento total das sete empresas brasileiras que mais investem em inovação no Brasil representa $0,61 \%$ do total de gastos com P\&D nas 1000 identificadas no ranking. As brasileiras que fazem parte do ranking são: Vale do Rio Doce, na $81^{\text {a }}$ colocação; Petróleo Brasileiro S.A., na $92^{\mathrm{a}}$ posição; CPFL Energia, na $634^{\mathrm{a}}$ colocação; Gerdau S.A., como a $640^{\mathrm{a}}$; Totvs S.A., na $750^{\mathrm{a}}$ posição; Embraer S.A., na $859^{\mathrm{a}}$ colocação, e Cia. Paraense de Energia, como a $952^{\text {a }}$ (BOOZ\&Co., 2012, p.12).
\end{abstract}

Pacheco (2011) aponta como um dos problemas no incentivo às atividades de $\mathrm{P} \& \mathrm{D}$ o regime fiscal favorecido da Lei do Bem, por estar centrado no Imposto de Renda de Pessoa Jurídica e na Contribuição Social sobre o Lucro Líquido, circunscrevendo-se a um número limitado (mas importante) de empresas que se inserem no regime tributário do lucro real.

Das 24 companhias que investem em P\&D, duas (Bermatech e Positivo Inf) são do setor de informática, portanto não poderiam se beneficiar da Lei do Bem, e outras duas (BRF Foods e CPFL Energia) são Holdings Operacionais que não investem diretamente em P\&D, mas por intermédio de suas controladas. Assim, essas empresas foram excluídas da próxima etapa. Portanto, a população de empresas em que se vai buscar identificar a razão da não utilização dos benefícios fiscais da Lei do Bem é composta de 20 empresas.

\title{
4.3 Razão da Não Utilização dos Incentivos Fiscais da Lei do Bem em 2010
}

Dos questionários encaminhados às vinte (20) empresas da população, participaram efetivamente desta etapa oito (8), o equivalente a $40 \%$ da população pesquisada. Do exposto na Tabela 2 pode-se inferir que as empresas listadas no segmento novo mercado da BM\&FBovespa que investiram em P\&D em 2010 e não se beneficiaram da Lei do Bem não o fizeram ou porque estavam com problemas fiscais (cinco empresas), ou seja, não apresentavam regularidade em relação aos tributos, ou porque fecharam o ano de $2010 \mathrm{com}$ prejuízo físcal (três empresas). Esse resultado vai de encontro aos achados de Bergamaschi (2009), que apontaram que as empresas que não se beneficiaram dos incentivos fiscais previstos na Lei 11.196/05 e no Decreto 5.798/06 não o fizeram em razão da falta de conhecimento, sinalizando a necessidade de ações efetivas entre o setor público e privado para superar essa barreira.

Tabela 2 - Razão da não utilização dos incentivos fiscais da Lei do Bem em 2010

\begin{tabular}{|c|c|}
\hline Razão da não utilização & Frequência \\
\hline - $\quad$ Desconhece a Lei do Bem & 0 \\
\hline - Estava com problemas fiscais (irregularidades fiscais) & 5 \\
\hline - Fechou o ano de 2010 com prejuízo fiscal & 3 \\
\hline $\begin{array}{l}\text { - Não enviou o Formulário para Informações sobre as atividades de Pesquisa } \\
\text { Tecnológica e Desenvolvimento de Inovação Tecnológica (FORMP\&D) em } \\
\text { tempo hábil }\end{array}$ & 0 \\
\hline - Outros & 0 \\
\hline
\end{tabular}

Fonte: elaborado pelos autores (2012). 
Como o foco da presente pesquisa foram as empresas privadas de capital aberto listadas no segmento novo mercado de governança corporativa da BM\&FBovespa, era de se esperar que o desconhecimento da Lei e a não participação por não encaminhamento do formulário em tempo hábil não seriam razões, pressupostos estes confirmados, conforme exposto na Tabela 1 acima.

Vale destacar que Koruki (2010), em entrevistas com 11 gestores que atuavam em diversos segmentos, sinalizou a exigência de regularidade fiscal como um dos principais fatores que impedem as empresas de utilizarem o Incentivo Fiscal da Inovação Tecnológica.

\section{Conclusão}

No plano teórico a pesquisa dissertou acerca da Inovação Tecnológica, Pesquisa e Desenvolvimento, Incentivos Fiscais e a Lei do Bem, ressaltando-se que a Pesquisa e Desenvolvimento, P\&D, é uma variável Proxy para se avaliar a Inovação das empresas.

$\mathrm{Na}$ pesquisa empírica, verificou-se que, em 2010, das 125 empresas no Brasil listadas no Novo Mercado, 19 (correspondente a 15\%) se beneficiaram da Lei do Bem, sendo 18 localizadas nas regiões sudeste e sul do país.

A pesquisa verificou ainda que das 125 empresas listadas no segmento novo mercado de governança corporativa, 43 investiram em P\&D, sendo que 24 empresas não constavam na listagem do Relatório Anual da Utilização dos Incentivos do MCTI e 19 empresas se beneficiaram da Lei do Bem.

Das 20 empresas pesquisadas, ou seja, que investiram em P\&D e não se utilizaram da Lei do Bem, 8 participaram da pesquisa e todas elas afirmaram que não se beneficiaram ou porque estavam com problemas fiscais, ou porque fecharam o ano de $2010 \mathrm{com}$ prejuízo fiscal.

Portanto, conclui-se que as companhias que investiram em P\&D e não se utilizaram da Lei do Bem não se beneficiaram ou porque estavam com problemas fiscais, ou porque fecharam o ano de 2010 com prejuízo fiscal. Esta conclusão suscita reflexões pelas entidades governamentais, pois as empresas podem estar nesta condição temporariamente. Acredita-se que a restrição poderia ser aplicada apenas às empresas que já viessem apresentando prejuízo fiscal há mais de três anos seguidos. Como contribuição no campo teórico foram investigadas as causas para a não utilização dos incentivos fiscais mesmo quando as companhias investiram em $P \& D$, o que vem a preencher uma lacuna de pesquisa.

$\mathrm{O}$ aumento consistente tem sido em indicadores científicos, como formação de pósgraduados e participação em publicações indexadas. Já em relação à escala dos incentivos à inovação, estes têm sido acessados por poucas empresas, mesmo considerando o reduzido grupo de empresas inovadoras no Brasil. Araújo (2012, p.39) ressalta que "é preciso estudar as causas para esta baixa demanda".

Ressalta-se, ainda, que os dois pressupostos foram confirmados, ou seja, o desconhecimento da Lei do Bem ou o não atendimento burocrático das exigências da Lei não foram motivos para o não aproveitamento dos benefícios da Lei do Bem.

Como limitação da pesquisa, registra-se que poder-se-ia ter obtido um maior índice de respostas, apesar de se ter tomado precauções para se obter um bom índice de encaminhamentos (questionário não extenso, e-mails individualizados e dirigidos aos executivos chave da empresa). Provavelmente a coleta nos meses de novembro e dezembro, período de esforço de atingimento de metas e fechamento de balanço fiscal, pode ter contribuído. De qualquer forma, $40 \%$ de respostas podem ser considerados razoáveis para o tipo de empresa pesquisada.

Como recomendação para novas pesquisas, sugere-se: 
(1) investigar até que ponto o critério de restrição à participação da Lei do Bem por prejuízo fiscal não está desincentivando $\mathrm{P} \& \mathrm{D}$ no Brasil, pois as empresas podem estar nesta condição temporariamente e, como a maturação de uma operacionalização produtiva de uma P\&D tem um prazo de médio e longo prazo, isto pode implicar na fragilidade da competitividade internacional das empresas instaladas no Brasil;

(2) dar continuidade à pesquisa investigando as companhias listadas em outros níveis diferenciados da BM\&FBovespa, por meio de uma análise comparativa dos segmentos Nível 1 de Governança Corporativa, Nível 2 de Governança Corporativa e Novo Mercado.

(3) Investigar o tema nas empresas de informática de capital aberto, posto que é um dos setores que mais investe em P\&D no mundo.

A importância deste estudo decorre do fornecimento de informações atuais e significativas das razões para as empresas não estarem se beneficiando dos incentivos fiscais à inovação tecnológica, tema que até agora vinha sendo negligenciado pelos pesquisadores. Espera-se, assim, que os conhecimentos adquiridos a partir desta investigação possam contribuir para o futuro desenvolvimento desta linha de pesquisa, bem como promover nas entidades uma reflexão para a solução dos entraves apresentados.

\section{Referências}

ANPEI. Indicadores de Pesquisa e Desenvolvimento: síntese dos resultados. São Paulo: ANPEI, 2007.

ARAÚJO, Bruno Cesar. Políticas de apoio à inovação no Brasil: uma análise da sua evolução recente. Rio de Janeiro: Ipea - Instituto de Pesquisa Econômica Aplicada, 2012.

ATKINSON, R.D. Expanding the R\&E tax credit to drive innovation, competitiveness and prosperity. Journal of Technology Transfer. Indianapolis, Netherlands, Indianapolis, v. 32, n. 6, p. 617-628, 2007. doi:10.1007/s10961-007-9046-y.

BARBOSA, Denis Borges. Incentivos fiscais à inovação. Apostila. 2006. Disponível em: $<$ http://www.inovacao.usp.br/images/pdf/Incentivos\%20Fiscais\%20a\%20Inovacao\%20\%20Bases\%20da\%20Tributacao\%20IRPJ.pdf>. Acesso em: 01 mar. 2012.

BARBOSA, R. K. Eco-inovações na Universidade: uma análise das patentes da Universidade Estadual de Campinas. 2011. 129 f. Dissertação (Mestrado em

Desenvolvimento Econômico)-Universidade Estadual de Campinas, Instituto de Economia, Campinas, 2011.

BARDIN, L. Análise de conteúdo. Lisboa: Edições 70, 2002.

BASTOS, V. D. Fundos Públicos para Ciência e Tecnologia. Revista do BNDES. Rio de Janeiro, v. 10, n. 20, dez. 2003. Disponível em: http://www.bndes.gov.br. Acesso em: 20 out. 2012.

BECKER, Howard S. 1997. Métodos de pesquisa em ciências sociais. 3 ed. São Paulo: 
Hucitec.

BERGAMASCHI, Eloísio Andrey. Inovação tecnológica e incentivos fiscais no setor de serviços de telecomunicações. 2009. 135 f. Dissertação (Mestrado) - Curso de PósGraduação em Administração, Departamento de Escola de Administração, Universidade Federal do Rio Grande do Sul, Porto Alegre, 2009.

BOOZ\&Co. Investimentos em Pesquisa \& Desenvolvimento no mundo crescem 9,6\% e voltam a níveis pré-recessão, revela estudo da Booz \& Company. 2012. Disponível em: $<$ http://www.booz.com/br/home/42559077/mostrar/51324088?pg=all >. Acesso em: 05 dez. 2012.

BRASIL. Presidência da República. Decreto $n^{0}$ 5.798, de 7 de junho de 2006. Disponível em: $<$ http://www.mct.gov.br>. Acesso em: 20 out. 2012.

BRASIL. Ministério da Ciência, Tecnologia e Inovação - MCTI. Relatório Anual da Utilização dos Incentivos Fiscais. Ano Base 2010. Lei nº 11.196/05 - Lei do Bem. Brasília DF, dez. 2011.

CABRAL, J. E. de Oliveira. Survey on Technological Innovative Behavior in the Brazilian Food Industry. Scientometrics, Springer Netherlands, v. 42, n. 2, p.129-169, 1998. doi:10.1007/BF02458353.

CALZOLAIO, A. E. ; DATHEIN, R. Políticas Fiscais de Incentivo à Inovação: uma avaliação da Lei do Bem. In: ENCONTRO DE ECONOMIA DA REGIÃO SUL,15., 2012, Porto Alegre. Anais... Porto Alegre: ANPEC SUL, 2012.

CERVO, A. L.; BERVIAN, P. A.; DA SILVA, R. Metodologia Científica. 6. ed. São Paulo: Pearson Prentice Hall, 2007.

CGEE/ANPEI. Os novos instrumentos de apoio à inovação: uma avaliação inicial. Brasília: Centro de Gestão e Estudos Estratégicos - Associação Nacional de Pesquisas e Desenvolvimento, 2008.

CIPOLLA, J. H.; CAVALCANTI, M.; SOUZA, R. C. Compartilhamento e Competição: um estudo da inovação e tecnologia na área cerâmica. In: COSTA, B. C.; ALMEIDA, M. R. (Org.). Modelos e Inovações em Estratégia. São Bernardo do Campo: Universidade Metodista de São Paulo, 2007.

COELHO, M. I. B de A. Incentivos fiscais à P\&D: a lei do bem nos Estados do Amazonas e Pará. T\&C Amazônia, Manaus/AM, ano IX, n. 20, I Semestre de 2011. Disponível em: $<$ http://www.fucapi.br/tec/imagens/revistas/010_ed20_inovacao_tecnologica_no_estado.p df> Acesso em: 25 out. 2012.

COLLIS, J.; HUSSEY,R. Pesquisa em administração: Um guia prático para alunos de graduação e pós-graduação. 2.ed. Porto Alegre: Bookman, 2005. 
CORREIA, E.; MOITA, R. Gasto em P\&D e poder de mercado: teoria e evidência para o Brasil. Pesquisa e Planejamento Econômico, IPEA, v. 14, n. 1, abr. 2011.

CRISÓTOMO, V. L.; GONZÁLES, E. V. Possível Reação do Mercado Brasileiro aos Investimentos em P\&D. Revista de Administração Mackenzie, São Paulo, v. 7, n.1, p. 96$114,2006$.

ÉPOCA NEGÓCIOS. Companhias do país em bolsa gastam 10,5\% mais em P\&D. Revista Época Negócios. Economia/Tecnologia, 2011. Disponível em:

$<$ http://epocanegocios.globo.com/Revista/Common/0,ERT274828-16357,00.html $>$. Acesso em: 05 dez. 2012.

FORMIGONI, Henrique. A influência dos incentivos fiscais sobre a estrutura de capital e a rentabilidade das companhias abertas brasileiras não financeiras. 2008. Tese (Doutorado em Controladoria e Contabilidade: Contabilidade) - Faculdade de Economia, Administração e Contabilidade, Universidade de São Paulo, São Paulo.

GONDIN, Linda M. P.; LIMA, Jacob Caros. A Pesquisa como Artesanato Intelectual: considerações sobre método e bom senso. João Pessoa: Manufatura, 2002.

HALL, Bronwyn H.; MAIRESSE, Jacques; MOHNEN, Pierre. Measuring the Returns to R\&D. In: HALL, B. H.; ROSENBERG, N. (Org.). Handbook of the Economics of Innovation, 2010. Disponível em:

$<$ http://elsa.berkeley.edu/ bhhall/papers/HallMairesseMohnen09_rndsurvey_HEI.pdf $>$. Acesso em: 10 jun. 2012.

HARADA, K. Incentivos fiscais: limitações constitucionais e legais. Âmbito Jurídico, Rio Grande, v. 94, 2011. Disponível em: <http://www.ambito-

juridico.com.br/site/index.php?n_link=revista_artigos_leitura\&artigo_id=10645>. Acesso em: 15 mar. 2012.

HJALAGER, A. Innovation Patterns in Sustainable Tourism: An analytical typology. Tourism Management, Elsevier, v. 18, n. 1, p. 35-41, 1997. doi.org/10.1016/S02615177(96)00096-9.

IEDI. Instituto de Estudos para o Desenvolvimento Industrial. Investimentos em Ciência, Tecnologia e Inovação na OCDE e nos BRICs. Carta IEDI n. 344, published in 23rd Dec. 2008. Disponível em: <www.iedi.org.br>. Acesso em: 10 abr. 2012.

JENSEN, J.; MENEZES FILHO, N.; SBRAGIA, R. Os Determinantes dos Gastos em P\&D no Brasil: uma análise com dados em painel. Estudos Econômicos, São Paulo, v. 34, n. 4, p. 661-691, out./dez. 2004. http://dx.doi.org/10.1590/S0101-41612004000400002.

KEMP, René; SMITH, K.; BECHER, G. How should we study the relationship between environmental regulation and innovation? In: IPTS Report EUR 19827. Sevilla: The European Commission, DG JRC, 2000.

KUROKI, Andreos Henrique. Utilização pelas empresas do incentivo fiscal da inovação 
tecnológica. 2010. 122 f. Dissertação (Mestrado em Controladoria Empresarial)-Programa de Pós-Graduação em Ciências Contábeis, Universidade Presbiteriana Mackenzie, São Paulo, 2010.

MARTIN, A. R. A Atividade de P\&D na Empresa: o caso da indústria petroquímica.

Polímeros: Ciência e Tecnologia, São Carlos/SP, v. 11, n. 2, p. 1-6, 2001. DOI: http://dx.doi.org/10.1590/S0104-14282001000200003.

MOREIRA, N.V.A. et al. A inovação tecnológica no Brasil: os avanços no marco regulatório e a gestão dos fundos setoriais. REGE - Revista de Gestão USP, São Paulo v. 14, 2007. DOI: http://dx.doi.org/10.5700/issn.2177-8736.rege.2007.36580. Disponível em: $<$ http://www.revistasusp.sibi.usp.br/pdf/rege/v14nspe/v14espa3.pdf $>$. Acesso em: 20 out. 2012.

OCDE. Perspectivas da Tecnologia da Informação: as tecnologias da comunicação e da informação e a economia da informação. São Paulo: Senac, 2003.

Manual de Oslo: proposta de diretrizes para coleta e interpretação de dados sobre inovação tecnológica. 2004. Disponível em:

$<$ http://www.finep.gov.br/imprensa/sala_imprensa/manual_de_oslo.pdf $>$. Acesso em: 01 mar. 2012.

PACHECO, Carlos Américo. O financiamento do gasto em P\&D do setor privado no Brasil e o perfil dos incentivos governamentais para P\&D. Revista USP, São Paulo, n. 89, p. 256-278, mar./maio, 2011.

PERDOMO-ORTIZ, J.; GONZÁLEZ-BENITO, J.; GALENDE J. Total quality management as a forerunner of business innovation capability. Technovation, Elsevier, v. 26, n.10, p. 1170-1185, 2006. DOI: 10.1016/j.technovation.2005.09.008.

QUIVY, Raymond; CAMPENHOUDT, Luc Van. Manual de Investigação em Ciências Sociais. 5 ed. Portugal: Gradativa, 2008.

ROCHA, M. C.; SOARES, M.; CASSONI, K. Um Olhar da Inventta: a eficiência dos mecanismos de fomento à inovação no Brasil. Radar Inovação, Inventta, fev. 2011. Disponível em: $<\mathrm{http}: / /$ inventta.net/wp-content/uploads/2011/02/Um-olhar-da-Inventta_aeficiencia-dos-mecanismos-de-fomento-a-inovacao-no-Brasil.pdf $>$. Acesso em: 01 mar. 2012.

SCHIMIDT, P.; FERNANDES, L. A.; SANTOS, J. L. Fundamentos da avaliação de ativos intangíveis. São Paulo: Atlas, 2006.

SCHUMPETER, J. A. Teoria do desenvolvimento econômico. São Paulo: Abril Cultural, 1982.

Teoria do desenvolvimento econômico: uma investigação sobre lucros, capital,

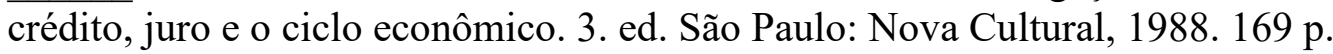


SENNES, R. Inovação no Brasil: políticas públicas e estratégias empresariais. 2011.

Disponível em:

$<$ http://www.interfarma.org.br/site2/images/Site\%20Interfarma/Informacoesdosetor/Publicac oes/ProspectivainovacaoEstrategiasPublicasePrivadas.pdf>. Acesso em: 10 ago. 2012.

SILVERMAN, David. 2009. Interpretação de dados qualitativos: métodos para análise de entrevistas, textos e interações. Porto Alegre: Artmed, 2009.

STEVENSON, William J. Estatística Aplicada à Administração. São Paulo: Habra, 2001.

STICKNEY, C. P.; WEIL, R. L. Contabilidade Financeira: uma introdução aos conceitos, métodos e usos. São Paulo: Atlas, 2010.

STRAUSS, Anselm; CORBIN, Juliet. Pesquisa qualitativa: técnicas e procedimentos para o desenvolvimento de teoria fundamentada. 2 ed. Porto Alegre: Artmed, 2008.

TRIGUeIRO, M. G. O Clone de Prometeu. Brasília: UnB, 2002.

ZUCOLOTO, G. F. Lei do Bem: impactos nas atividades de P\&D no Brasil. Radar Tecnologia, Produção e Comércio Exterior, Ipea, v. 2, n.1, p. 14-20, 2010.

\section{APÊNDICE A - Carta convite e Questionário}

Prezado(a)Senhor(a),

Estamos realizando estudo sobre Incentivos Fiscais à Inovação Tecnológica. A pesquisa tem o objetivo de identificar as razões da não utilização de incentivos fiscais à inovação tecnológica da Lei do Bem por empresas privadas de capital aberto, listadas no segmento Novo Mercado da BM\&FBovespa.

O sucesso do estudo depende da participação dos diretores de relações com investidores das empresas pesquisadas, que consistirá no preenchimento de questionário composto de uma questão que permitirá identificar a razão da empresa não ter se beneficiado da Lei do Bem, mesmo tendo investido em P\&D no ano de 2010. O tempo estimado para responder ao questionário é de aproximadamente dois minutos.

O questionário pode ser respondido no próprio corpo do e-mail (segue abaixo), como também estamos enviando como anexo.

Para maiores esclarecimentos, ou para tratar sobre outras formas de envio do questionário, colocamo-nos à disposição pelos telefones: (85) 8778-5589 (Elisangela, pesquisadora), (85) 8706-9691 (Oderlene Oliveira, orientadora).

Antecipamos agradecimentos por sua participação.

\section{QUESTIONÁRIO}

O presente questionário se aplica às empresas listadas no segmento Novo Mercado da BM\&FBovespa que apresentaram investimento em P\&D, no exercício de 2010, nos relatórios anuais, relatório da administração ou relatório de sustentabilidade, porém não se beneficiaram da Lei do Bem, de acordo com o relatório anual da utilização dos incentivos fiscais. Assim, 
questiona-se:

1) Por que a empresa não se utilizou do incentivo fiscal da Lei do Bem, nº 11.196/2005, já que investiu em P\&D no exercício de 2010?

a) ( ) desconhece a lei

b) ( ) estava com problemas fiscais (irregularidade fiscal da pessoa jurídica em relação aos tributos)

c) ( ) fechou o ano de 2010 com prejuízo fiscal

c) ( ) não enviou o Formulário para Informações sobre as atividades de Pesquisa Tecnológica e Desenvolvimento de Inovação Tecnológica (FORMP\&D) em tempo hábil

d) ( ) é uma empresa do setor de informática

e) ( ) outros: 